\title{
Morphological and Genetic Characterization of the First Species of Thalassodrilides (Annelida: Clitellata: Naididae: Limnodriloidinae) from Japan
}

\author{
Takaaki Torii ${ }^{1,4}$, Christer Erséus², Svante Martinsson², and Mana Ito ${ }^{3}$ \\ ${ }^{1}$ IDEA Consultants Inc., 1334-5 Riemon, Yaizu, Shizuoka 421-0212, Japan \\ E-mail: ttakaaki@ideacon.co.jp \\ ${ }^{2}$ University of Gothenburg, Department of Biological and Environmental Sciences, Box 463, SE-405 30 Göteborg, Sweden \\ ${ }^{3}$ National Research Institute of Fisheries and Environment of Inland Sea, Fisheries Research Agency, \\ 2-17-5 Maruishi, Hatsukaichi, Hiroshima 739-0452, Japan \\ ${ }^{4}$ Corresponding author
}

(Received 17 May 2016; Accepted 13 October 2016)

\begin{abstract}
A species of marine limnodriloidine oligochaete, Thalassodrilides cf. briani Erséus, 1992, is recorded from gravelly sand sediments of the subtidal zone in Ehime Prefecture, Japan. The present material agrees with the original description of T. briani, which was first found at Hong Kong, with the exception that the copulatory sacs are oval; not slender. Despite the lack of genetic data for the Hong Kong population, we conclude that the Japanese specimens are conspecific with it, or at least very closely related, based on morphological considerations. This is the first record of the genus Thalassodrilides Brinkhurst and Baker, 1979 in Japan. The phylogenetic relationships between T. cf. briani and three other species of Thalassodrilides are estimated, based on partial DNA sequences of the mitochondrial cytochrome $c$ oxidase subunit I (COI) gene and the complete nuclear ribosomal Internal Transcribed Spacer (ITS) region, using two members of the closely related genus Doliodrilus Erséus, 1984 as outgroups. The genetic analysis shows that $T$. cf. briani is a species delimited by both mitochondrial and nuclear data, and clearly separated from at least its closely related congeners in the Northwest Atlantic (Caribbean and adjacent areas).
\end{abstract}

Key Words: Oligochaeta, marine subtidal sediments, new record, taxonomy, molecular systematics, COI, ITS.

\section{Introduction}

Thalassodrilides Brinkhurst and Baker, 1979 is a relatively small genus of marine or brackish-water Naididae in the subfamily Limnodriloidinae. It was established by Brinkhurst and Baker (1979), and later Erséus (1990) revised it to include species of Limnodriloidinae with a reticulate blood plexus surrounding a widened and thick-walled part of the oesophagus in segment IX and a pair of complex, muscular, eversible pseudopenes. Erséus $(1981,1990)$ transferred Curacaodrilus Righi and Kanner, 1979 and Kaketio Righi and Kanner, 1979, to Thalassodrilides on the basis of this emended definition (see Erséus 1990). Six species of Thalassodrilides are recognized today as follows; T. belli (Cook, 1974), T. briani Erséus, 1992, T. bruneti Erséus, 1990, T. gurwitschi (Hrabě, 1971) (the type species, originally described as Limnodriloides gurwitschi Hrabě, 1971), T. ineri (Righi and Kanner, 1979), and T. milleri Brinkhurst and Baker, 1979. Among these, Erséus $(1981,1990)$ regarded T. milleri as incertae sedis or a nomen dubium.

Fifteen species of brackish-water or marine Naididae have been reported from Japan up to the present (Ohtaka 1987; Takashima and Mawatari 1996, 1998; Takashima 2000, 2001), but none of them belongs to this genus. This study documents the first Japanese record of Thalassodrilides, based on morphological and genetic information.

\section{Materials and Methods}

Specimen collecting. Worms were collected from bottom sediment next to a fish farm in an embayment on the Pacific coast of southwestern Shikoku, Japan. Bottom samples (depth $36.6 \mathrm{~m}$ ) were taken with an Ekman-Birge grab, and worms suspended in water in a tray were sucked up directly with pipettes. Sampling was qualitative. Live and fixed specimens were examined using a compound microscope. Specimens for morphological observation were fixed with either $10 \%$ formalin or $70 \%$ ethanol solutions, after being anesthetized in low concentrations of ethanol, and dehydrated in a graded ethanol series, cleared in methyl salicylate, and mounted whole onto slides in Canada balsam. Unless otherwise specified in the description, measurements refer to whole-mounted specimens. The drawings were made freehand with the aid of traced from a photo using a light box. Specimens for molecular phylogenetic study were fixed in $99 \%$ ethanol.

DNA sequencing and assembly. For the genetic analyses ten Japanese specimens of the species here described as Thalassodrilides cf. briani were selected together with four specimens of T. bruneti, two of T. belli, and two of an unidentified T. sp. For rooting the trees one specimen each of Doliodrilus fibrisaccus Wang and Erséus, 2004 and D. tener Erséus, 1984 were included. See Table 1 for details of all 


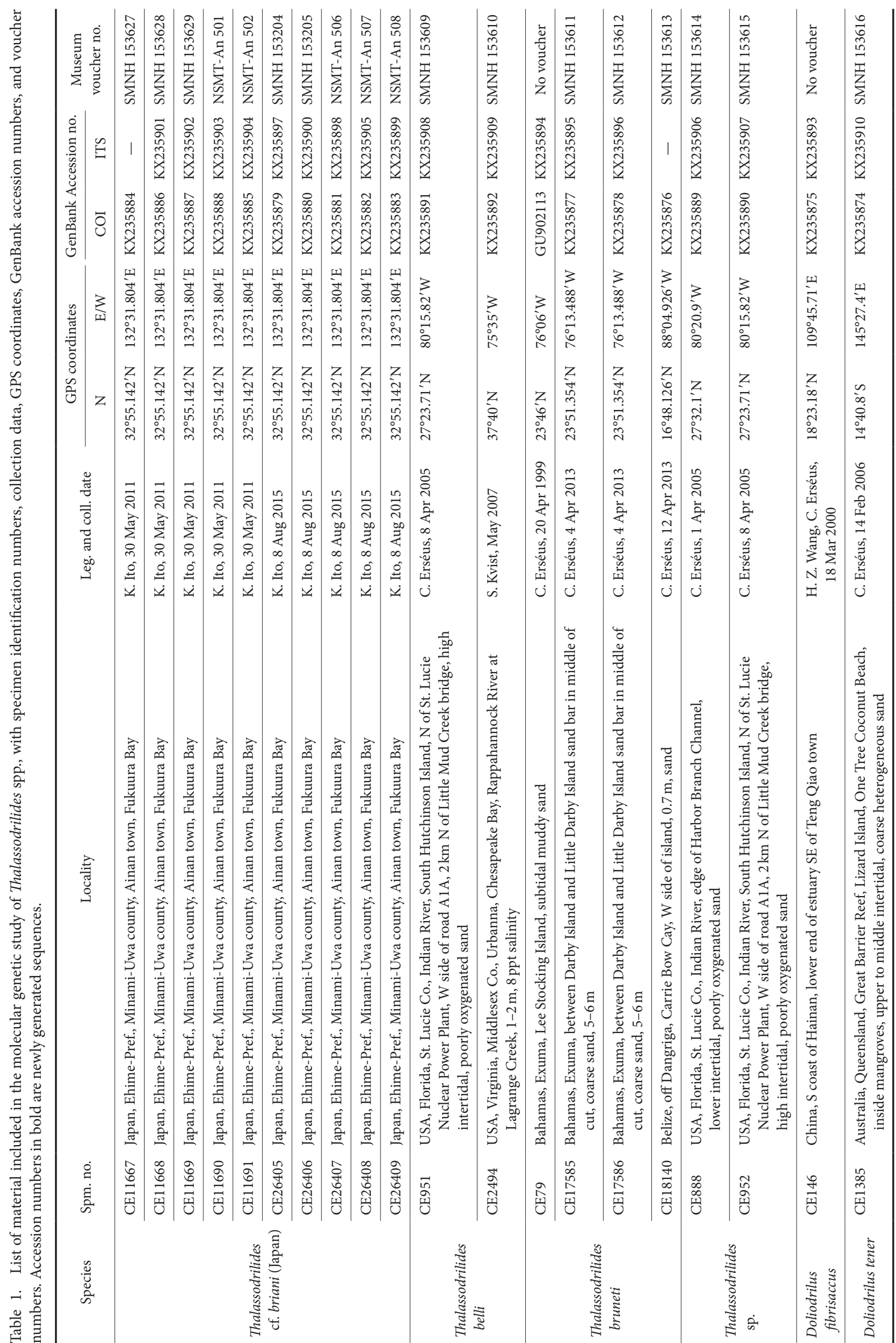


Table 2. Uncorrected pairwise genetic distances (in \%) for COI (below diagonal) and ITS (above diagonal), mean distances in parentheses.

\begin{tabular}{|c|c|c|c|c|c|c|c|}
\hline & Species & 1 & 2 & 3 & 4 & 5 & 6 \\
\hline 1 & D. tener $(n=1)$ & - & $15.0(15.0)$ & $12.9-15.3(13.7)$ & $16.0-16.1(16.0)$ & $13.1(13.1)$ & $12.9(12.9)$ \\
\hline 2 & D. fibrisaccus $(n=1)$ & $19.0(19.0)$ & - & $13.3-14.3(13.7)$ & $15.1-15.2(15.1)$ & $14.5(14.5)$ & $14.4-14.5(14.4)$ \\
\hline 3 & T. bruneti $(n=4 / 3)$ & $15.7(15.7)$ & $18.2-18.5(18.3)$ & - & $4.4-5.8(5.0)$ & $0.5-0.8(0.7)$ & $1.6-2.1(1.8)$ \\
\hline 4 & T. belli $(n=2)$ & $16.2-18.2(17.2)$ & $18.3-19.0(18.7)$ & $10.4-12.1(10.9)$ & - & $4.8-4.9(4.8)$ & $4.8-5.0(4.8)$ \\
\hline 5 & $T . \mathrm{sp} .(n=2)$ & $16.7(16.7)$ & $18.5-18.7(18.6)$ & $8.8-9.3(9.0)$ & $9.8-11.6(10.7)$ & - & $1.5-1.6(1.6)$ \\
\hline 6 & T. cf. briani (Japan) $(n=10 / 9)$ & $14.7-15.4(15.3)$ & $19.9-20.2(20.1)$ & $5.6-7.3(6.3)$ & $10.9-12.4(11.6)$ & $8.3-8.6(8.5)$ & - \\
\hline
\end{tabular}

specimens. DNA was extracted from the posterior ends of ethanol-preserved worms. DNA extraction, PCR amplification, and primers follow Martinsson et al. (2013). Two markers, the mitochondrial cytochrome $c$ oxidase subunit I (COI) gene and the complete nuclear ribosomal Internal Transcribed Spacer (ITS) region, were amplified. One of the COI sequences of T. bruneti was from Erséus et al. (2010) and downloaded from GenBank. Sequencing was carried out by Macrogen Inc. (Seoul, Korea) and Eurofins MWG Operon (Ebersberg, Germany). Sequences were assembled and aligned in Geneious Pro v. 7.1. (Biomatters Ltd.; http:// www.geneious.com). All sequences produced in this study are deposited in GenBank (Accession numbers in Table 1). Vouchers of sequenced specimens (i.e., anterior body parts mounted on microscope slides) are deposited in the National Museum of Nature and Science (NSMT), Tsukuba, Japan, and in the Swedish Museum of Natural History (SMNH), Stockholm, Sweden (see Table 1).

Distance analysis. Uncorrected pairwise genetic distances, including within-species and between-species means, were calculated for both the COI and ITS datasets in MEGA 6 (Tamura et al. 2013), using pairwise deletion for missing data (Table 2).

Gene tree estimation. Gene trees were estimated using Maximum Likelihood; the analyses were performed with PhyML 3.0 (Guindon and Gascuel 2003; Guindon et al. 2010) as implemented at the South of France Bioinformatics platform (http://www.atgc-montpellier.fr/). The automatic model selection using SMS (Smart Model Selection) with BIC (Bayesian Information Criterion) as the selection criterion was used; SPR+NNI was used for tree improvement. Branch support was calculated with the Chi-squared-based approximate Likelihood Ratio Test (aLRT) (Anisimova and Gascuel 2006) in PhyML. The same settings were used for both the COI and the ITS analyses. The trees were drawn in FigTree 1.4.2 (Rambaut 2014) and further edited in Adobe Illustrator.

Abbreviations in figures. aa: atrial ampulla; ad: atrial duct; cs: copulatory sac; eg: egg; ov: ovary; pr: prostate gland; sa: spermathecal ampulla; sb: sperm bundles; sd: spermathecal duct; sf: sperm funnel (with mass of spermatozoa); sp: spermathecal pore; vd: vas deferens.
Genus Thalassodrilides Brinkhurst and Baker, 1979

[New Japanese name: Naiwan-ito-mimizu-zoku]

Thalassodrilides cf. briani Erséus, 1992

[New Japanese name: Hime-naiwan-ito-mimizu] (Figs 1-2)

Thalassodrilides sp.: Ito et al. 2016: 340, fig. 1.

Thalassodrilides briani Erséus, 1992: 172-173, fig. 10 (morphologically similar).

Material examined. 4 mature specimens from the Seto Inland Sea, Fukuura Bay, Ainan town, Minami-Uwa county, Ehime Prefecture, Japan, $32^{\circ} 55^{\prime} 14.2^{\prime \prime} \mathrm{N}, 132^{\circ} 31^{\prime} 8.0^{\prime \prime} \mathrm{E}, 36.6 \mathrm{~m}$ depth, 17 November 2010 (NSMT-An 497-500); 5 mature specimens, 30 May 2011, other data as for NSMT-An 497-500 (NSMT-An 501-505); 4 mature specimens, $8 \mathrm{Au}-$ gust 2015, other data as for NSMT-An 497-500 (NSMT-An 506-509, SMNH 153204-153205).

Description of new material. Body color reddish, mostly reflecting blood color. Fixed and mounted specimens 6.8-9.1 mm long (5 specimens), 200-260 $\mu \mathrm{m}$ wide at clitellum. Segments 48-58. Prostomium round or somewhat triangular. Body wall naked, i.e., devoid of cuticular papillation. Clitellum extending over XI to mid XII. Chaetae sigmoid and bifid with upper tooth shorter and narrower than lower, with nodulus about $1 / 3$ of way from distal tip (Figs 1A, 2A); 3-5 chaetae per bundle anteriorly, 2-3 per bundle in postclitellar segments, but chaetae absent ventrally from XI in mature specimens. Ventral and dorsal chaetae shortest in II, longest in VI, gradually shortening from VIII on. Hair chaetae and modified genital chaetae absent. Male pores paired in line with ventral chaetae, posteriorly in XI. Spermathecal pores in X.

Brain in I-II, concave posteriorly, approximately 1.5 times as long as wide, length $165-180 \mu \mathrm{m}$, posterior width $88-94 \mu \mathrm{m}$. Pharyngeal glands in IV-V. Oesophagus enlarged in IX, and in this segment thick-walled with conspicuous blood plexus.

Sperm funnel (Figs 1B, C, 2B) 49-60 $\mu \mathrm{m}$ long and $36-45 \mu \mathrm{m}$ wide at ental margin, funnel wall becoming thinner posteriorly. Vas deferens thick-walled, rather short, entering apical end of atrium in XI. Atrial ampulla somewhat spindle-shaped, $48-67 \mu \mathrm{m}$ long, $20-32 \mu \mathrm{m}$ wide, with thin outer muscular layer and rather wide lumen, latter partly divided by thin horizontal septum into dorsal and ventral compartments (Figs 1B, C, 2B). In some pre-copulatory specimens, atrial ampulla somewhat lobed. Prostatic pad 
A
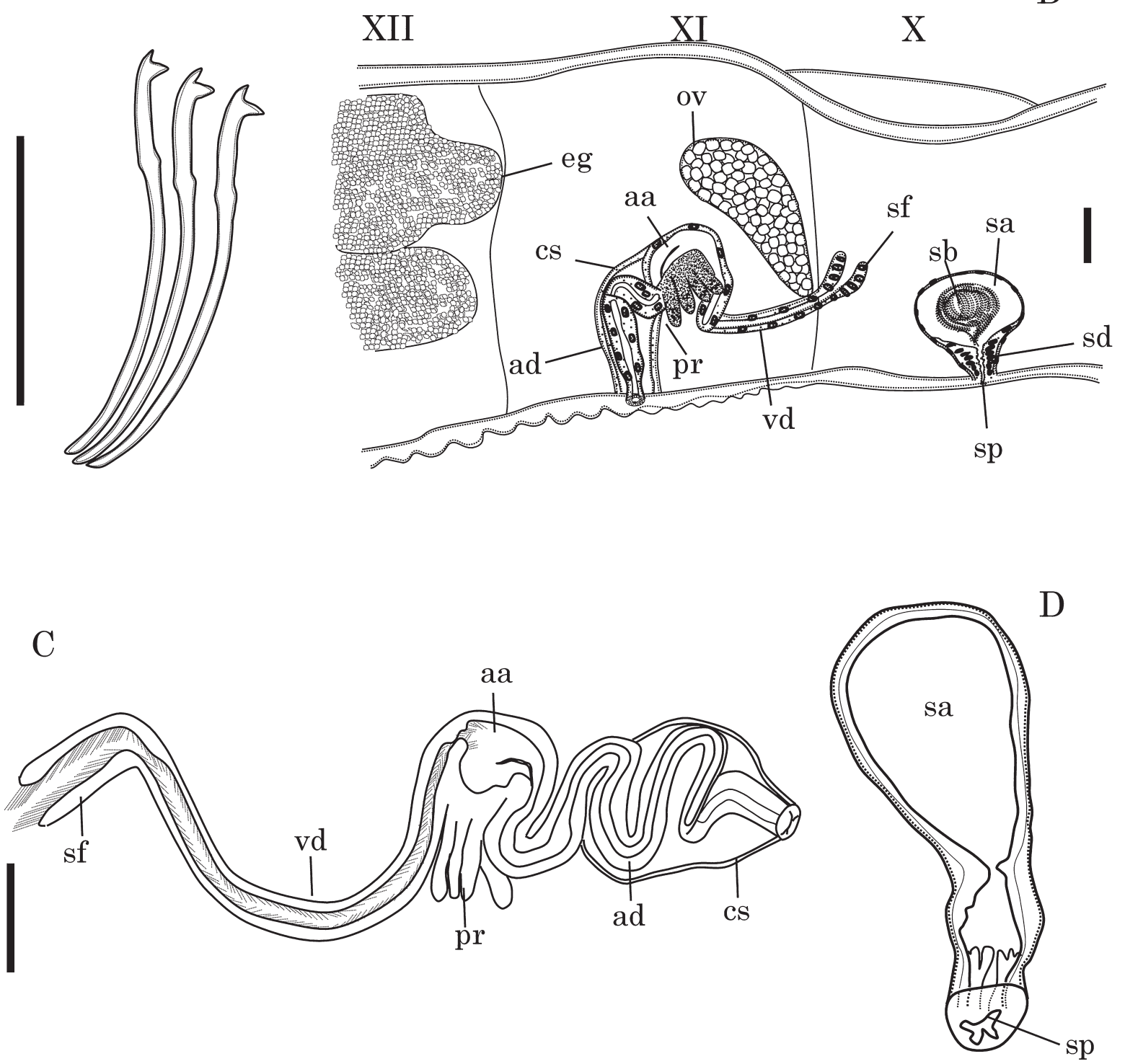

Fig. 1. Thalassodrilides cf. briani from Ehime Prefecture, Japan (NSMT-An 507), drawings from whole mounts. A, ventral chaetae from anterior segments; B, reproductive system in segments X-XII; C, detail of male reproductive structures from a live specimen; D, detail of spermatheca from a live pre-copulatory specimen. Scale bars: $50 \mu \mathrm{m}$.

inconspicuous, but extending along most of length of atrial ampulla. Prostate gland small, lobed. Atrial duct slender, slightly longer than ampulla, running inside somewhat pear-shaped, moderately muscular copulatory sac. Ental part of duct granulated, ectal part forming pseudopenis. Male pores not on protuberances when pseudopenes retracted. Egg sac unpaired in XIII-XV, well-developed, sometimes extending back to XVIII-XXI. One pair of testes in spermathecal segment $X$ and one pair of ovaries in atrial segment XI. Spermatheca composed of thick-walled, conical duct and thin-walled, oval ampulla. Duct usually shorter than wide (34-60 $\mu \mathrm{m}$ long, 48-62 $\mu \mathrm{m}$ maximum diameter), with no ectal glands. Ampulla 1/3 as wide as segment (120$282 \mu \mathrm{m}$ maximum diameter in post-copulatory worms) (Figs 1D, 2C, D), ectal duct sometimes with vestibule (Figs 1D, 2C). Ball-shaped mass (or bundles) of sperm in ampullar lumen (Figs 1D, 2D).
Habitat. The Japanese specimens were collected in the Pacific coast, next to a fish farm, in gravelly sand $(5.4 \%$ gravel, $92.5 \%$ sand, and $2.1 \%$ silt and clay). Acid volatile sulfide and loss on ignition $\left(600^{\circ} \mathrm{C}\right.$ for $\left.2 \mathrm{~h}\right)$ of the surface layer sediment were $0.2 \mathrm{mg} \mathrm{S} / \mathrm{g}$ and $8.6 \%$, respectively. It is very probable that fish farm waste had settled into the bottom.

Remarks. The new material agrees well with the original description of Thalassodrilides briani, a species so far only known from Hong Kong (southern China), with the exception that the copulatory sacs of our worms are not as slender as those described by the author (Erséus 1992). The horizontal atrial septum present in T. briani and T. cf. briani appears to be an unusual character, but it may have been overlooked in T. bruneti and T. gurwitschi. On morphological grounds only, we find it difficult to decide whether our $T$. cf. briani is the same as the proper T. briani; this can only be finally resolved by genetic information. Our Japanese 

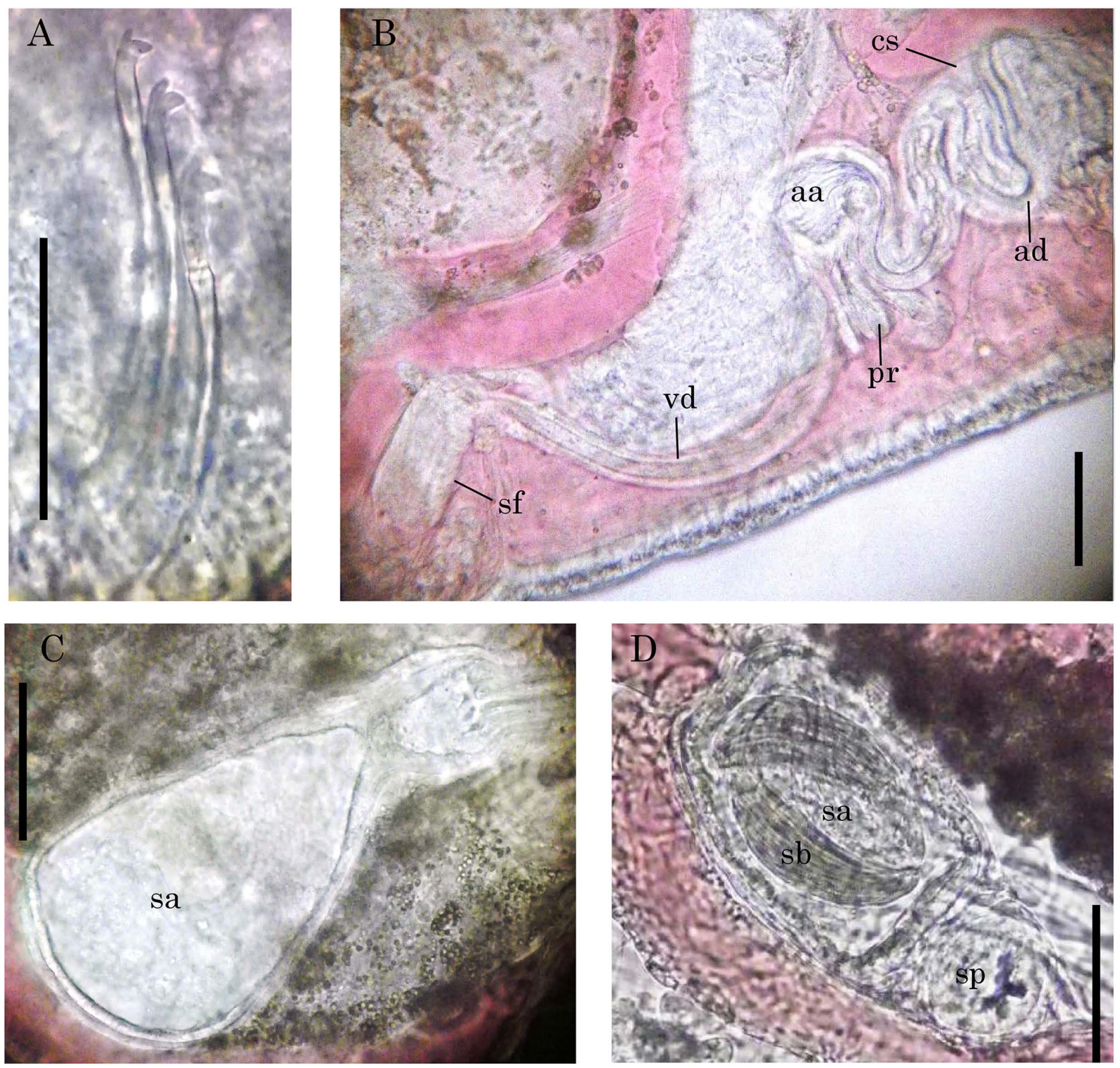

Fig. 2. Thalassodrilides cf. briani from Ehime Prefecture, Japan, microscopic photographs from live specimens. A, ventral chaetae from anterior segments; B, male reproductive structures; C, pre-copulatory spermatheca; D, mature (post-copulatory) spermatheca. Scale bars: $50 \mu \mathrm{m}$.

species also resembles the Belizean T. bruneti, with which it shares similar male ducts (including the simple, weakly muscular copulatory sacs). However, the absence of spermathecae is a useful character to identify T. bruneti as a different morphospecies. A morphological comparison between all the members of Thalassodrilides is shown in Table 3. Except for $T$. ineri, a large species with exceptionally elaborate atrial, penial, and spermathecal structures, and the fact that two nominal taxa (T. bruneti and T. gurwitschi) and one unidentified species ( $T$. sp.) lack spermathecae completely, the various species described to date are extremely difficult to discriminate morphologically from each other.

Distribution. Our T. cf. briani has so far only been found in Ehime Prefecture in southern Japan. Thalassodrilides briani per se is only known from a single locality in Hong Kong (Erséus 1992).

\section{Genetic Analysis}

DNA sequencing and assembly. COI was successfully sequenced from all 20 specimens, and ITS from 18 specimens. After trimming, the COI alignment was 605 bp long, and the ITS alignment 1386 bp long.

Distance analysis. The results are summarized in Table 2. In COI, no variation was observed among the Japanese specimens, which were separated from the specimens of the other included species of Thalassodrilides by $5.6-12.4 \%$ pairwise distances. The closest species to $T$. cf. briani was $T$. bruneti; these two species had a mean pairwise distance of 6.3\%. Mean pairwise distances among Thalassodrilides species varied from $6.3 \%$ to $11.6 \%$. Deep splits were observed within two of the included species, viz., T. bruneti with a maximum intraspecific pairwise distance of $5.0 \%$, and $T$. 


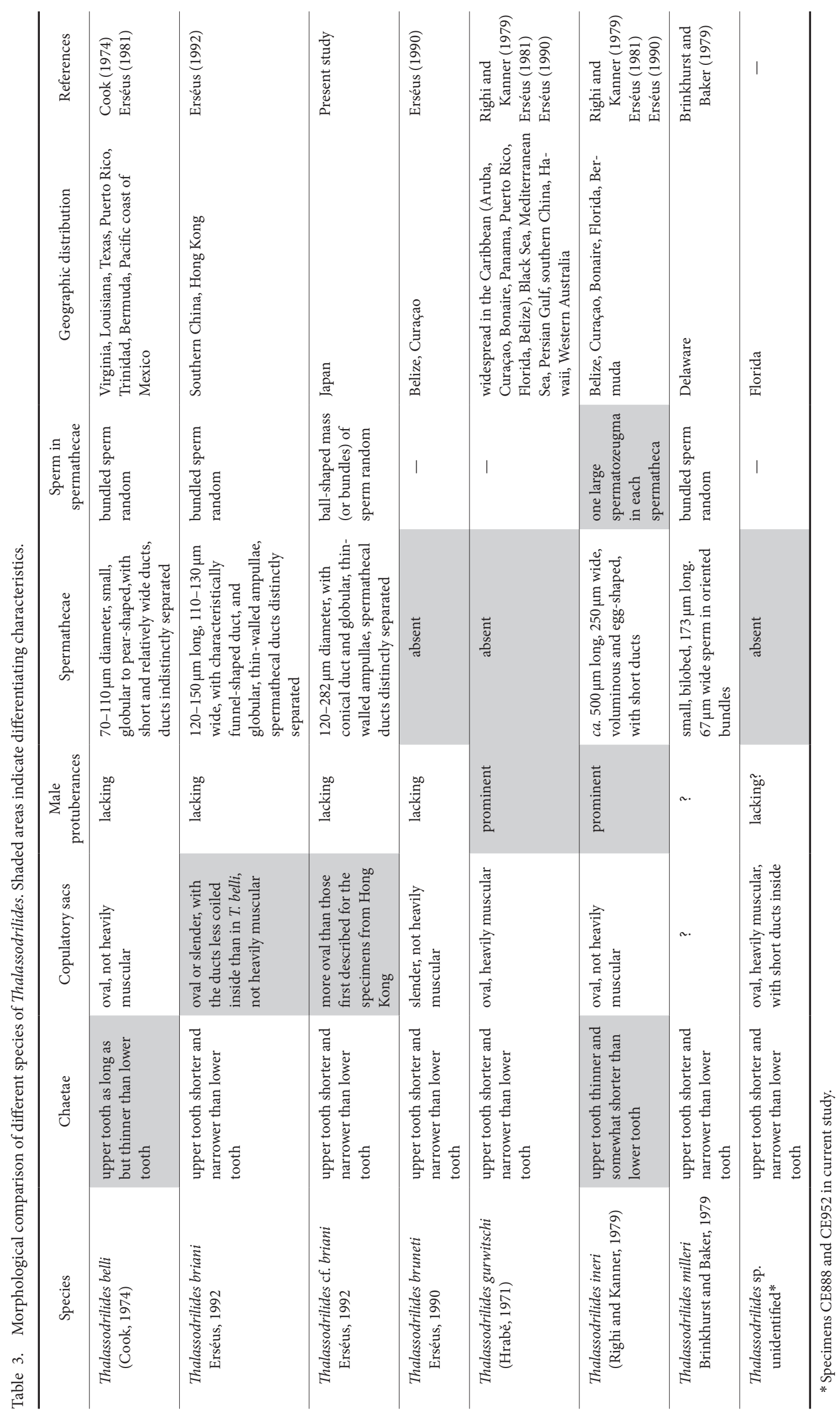


belli with an intraspecific distance of $11.4 \%$, i.e., a distance of the same magnitude as seen between species in this genus. The out-groups Doliodrilus fibrisaccus and D. tener were well separated from the Thalassodrilides species, with average mean distances between 15.3 and $20.2 \%$, and the out-groups were also well separated from each other (19\%).

In ITS, there were no differences among the specimens from Japan, and in general the distances between Thalassodrilides species were smaller than for COI, varying between 0.7 and $4.8 \%$. The Japanese specimens ( $T$. cf. briani) were closest to $T$. sp., with a mean difference of $1.6 \%$, and also close to T. bruneti, with a mean difference of $1.8 \%$. T. brunet $i$ and $T$. sp. were only $0.7 \%$ different from each other, and the distances between $T$. belli and the other Thalassodrilides species were greater (mean differences of $4.8-5 \%$ ). The variation within species was small, with a maximum of $0.2 \%$ in $T$. belli. The out-groups were well separated from the in-group, with mean differences of $12.9-16 \%$, and also well separated from each other (15\%).

Gene tree estimation. For the COI analysis the TN93 substitution model with 6 gamma shape parameters was selected, whereas for the ITS analysis the HKY 85 model with 6 gamma shape parameters was selected. Both analyses (Fig. 3) found Thalassodrilides to be monophyletic with maximum aLRT support, but because we include only a limited sample of out-groups, this was not a proper test of the monophyly of the genus. In the ITS tree (Fig. 3B), all species were recovered as monophyletic with maximum aLRT support, and in the COI tree (Fig. 3A), all species except T. belli were also recovered as monophyletic with maximum support. In the COI tree (Fig. 3A), (1) all relationships between species were unsupported, (2) a well-supported split was observed within T. bruneti, and (3) T. belli was not recovered as monophyletic and its terminal branches were (unexpectedly) long. In the ITS tree, T. belli was found as the sister to the remaining Thalassodrilides species, and T. cf. briani was found as the sister to a clade consisting of T. bruneti and $T$. sp. The splits observed within T. bruneti and T. belli in the COI analysis were not found in the ITS tree, but this may be due to our failure to obtain an ITS sequence for T. bruneti specimen CE18140, which was found as sister to the remaining $T$. bruneti in the COI tree.

\section{Discussion}

Based on morphological data, a species of Thalassodrilides that resembles the taxon $T$. briani, which was previously known from only a single site near Hong Kong (southern China), is here reported and described from Japan for the first time. We have shown that this Japanese species is distinctly delimited from many congeners by both mitochondrial and nuclear molecular markers. For the time being, however, we have no access to genetic information about specimens from the vicinity of $T$. briani's type locality, and we prefer to regard our new material as $T$. cf. briani rather than conclude it is identical to T. briani sensu Erséus (1992), especially as we noted some morphological differences be- tween the copulatory sacs of the two populations. Nevertheless, our results will facilitate further studies to ascertain the taxonomic status of $T$. cf. briani, once someone obtains the missing genetic information.

Vivien et al. (2015) recently showed that morphological studies may underestimate the diversity of aquatic oligochaetes inferred from genetic data. Within the limited samples of Thalassodrilides included in this study, we noted two cases of mitochondrial (COI) divergence within a morphospecies. In T. bruneti there was an approximately $5 \%$ split between a specimen from Belize (CE18140) and the remaining three specimens from the Bahamas. In T. belli there was a $11.4 \%$ split between specimens from Florida and Virginia (US east coast), and T. belli was not recovered as monophyletic in the COI tree. This may serve as a warning that T. briani and T. cf. briani are part of a complex of very similar species. On the other hand, the two T. belli specimens only differ by $0.2 \%$ in ITS, and we lack ITS data (see above) for the CE18140 individual of T. bruneti. It is possible that these two cases involve cryptic species, but without more data it is impossible to rule out deep intraspecific mitochondrial divergence, a phenomenon not uncommon for clitellates (e.g., Achurra and Erséus 2013; Martinsson et al. 2013).

With respect to their previously uninvestigated phylogenetic relationships, our analysis of four Thalassodrilides species based on the mitochondrial cytochrome $c$ oxidase subunit I and nuclear ribosomal internal transcribed spacer (ITS) region has shown that they form a genetically coherent group, which supports inferences based on morphological observations and taxonomic conclusions in the revision by Erséus (1990). In terms of ecological function, it is worth noting that Ito et al. (2016) recently revealed the ability of Japanese T. cf. briani (=their "Thalassodrilides sp.") to biotransform 1-nitronaphthalene, a nitrated polycyclic aromatic hydrocarbon. The worms, which were collected from the same site that was sampled in the present study, proved to have a superior ability to convert 1-nitronaphthalene into substances that were nontoxic to sensitive larval fish [Fundulus heteroclitus (Linnaeus, 1766), the mummichog], and furthermore, estimates of the worm population density at their sampling site were over 100,000 individuals per square meter. It is very probable that the very high densities of this species are related to effluent from the fish farm. In general, several Naididae are considered to have a high tolerance to organic toxins and may have a strong ability to degrade industrial pollutants. For example, Vorobev et al. (2010) reported that the aquatic naidid worm Limnodrilus hoffmeisteri Claparède, 1862 survived highly contaminated oil sediment and also had the ability to bioremediate oil from bottom sediment. In the case of microorganisms, efficient bioremediation is dependent on achieving adequate population density, metabolic capability, and physiological activity at the contaminated site (e.g., Sayler et al. 1982; Dinesh et al. 2015). It is very likely that the same holds true for the Japanese T. cf. briani. Further taxonomic and physiological studies of this species may thus facilitate its usefulness as a bioindicator of water quality, and its involvement in the de- 


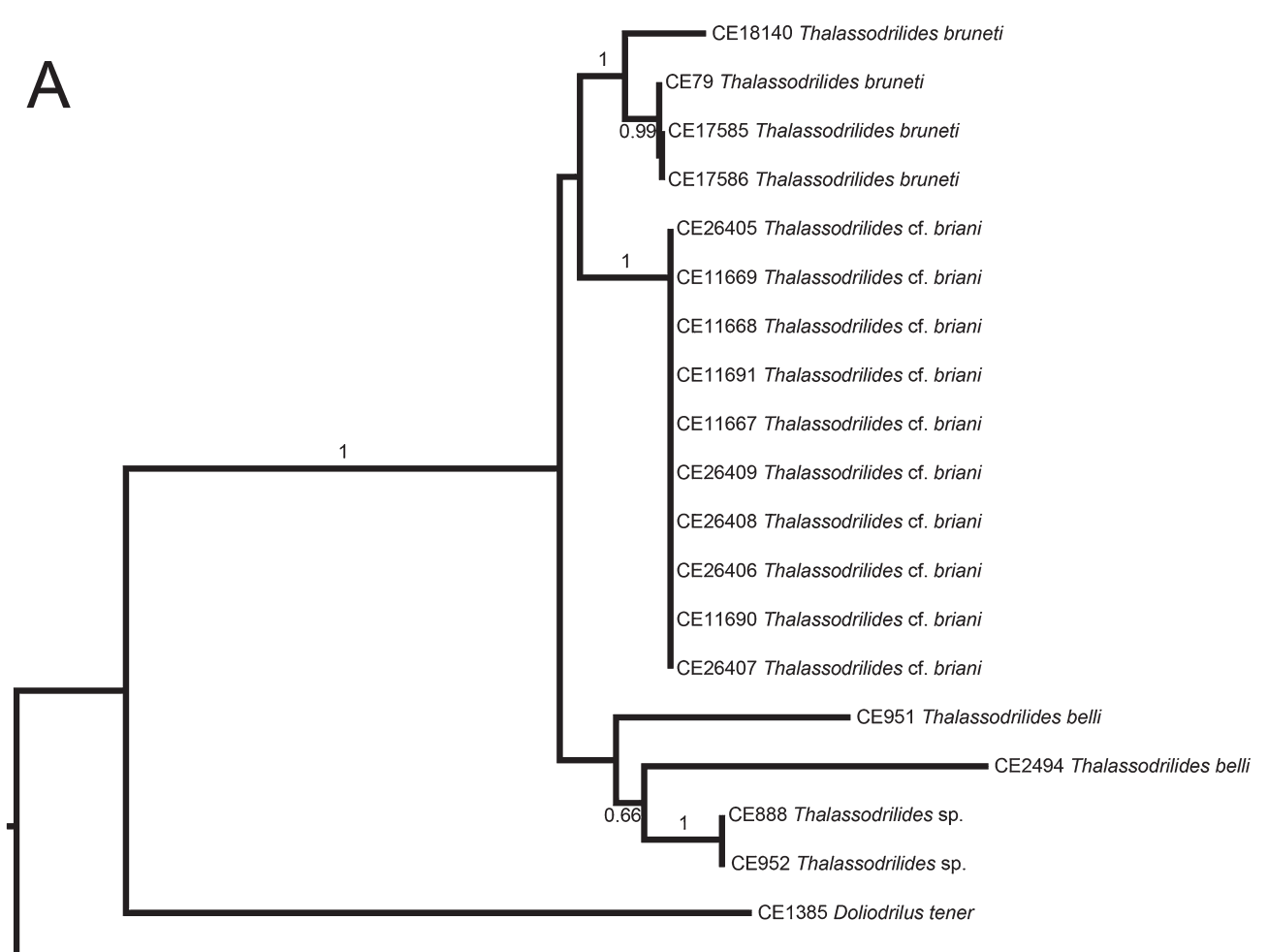

0.1

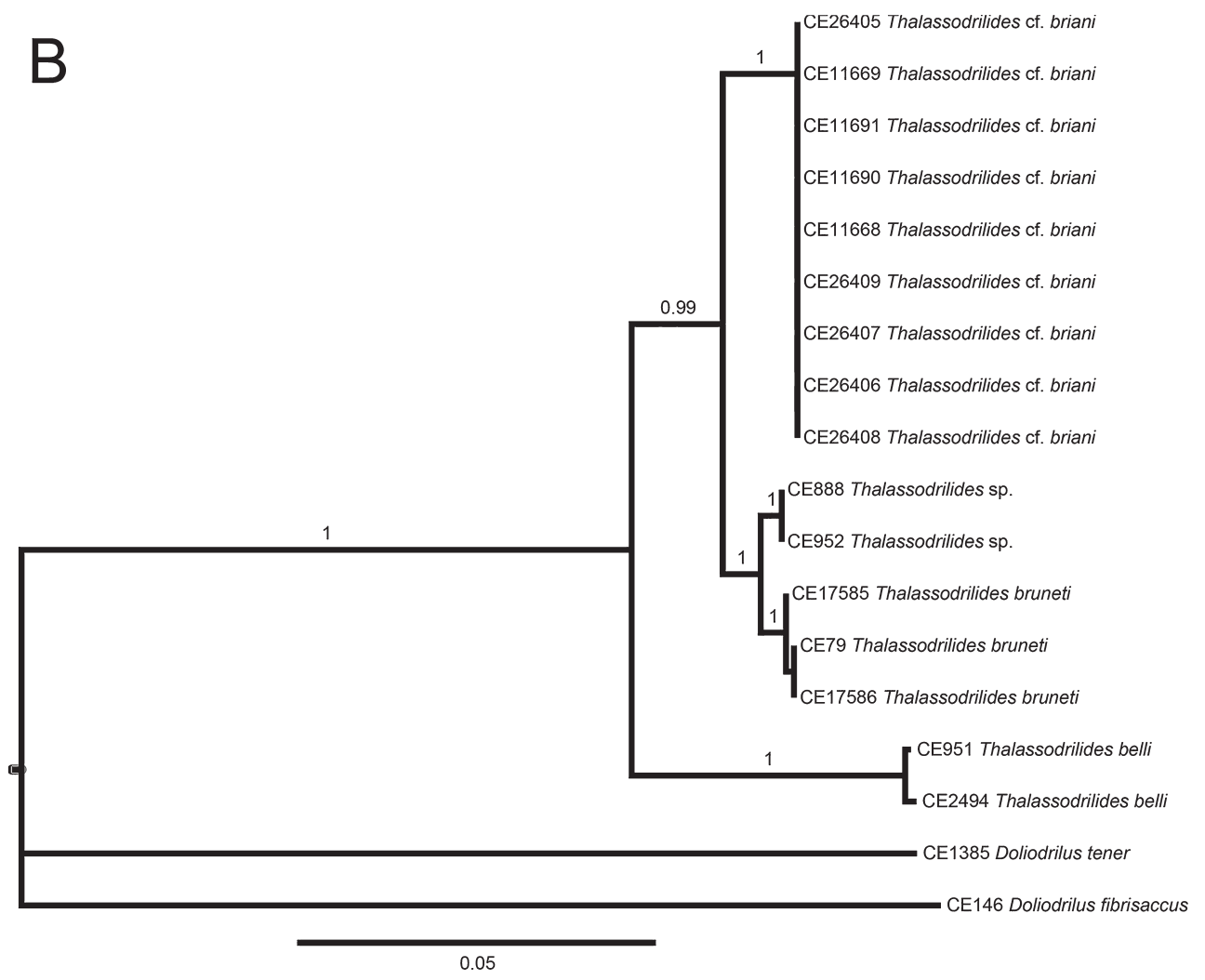

Fig. 3. Maximum likelihood gene trees estimated using PhyML. A, COI; B, ITS. Numbers at branches denote aLRT branch support. Scale shows estimated numbers of nucleotide substitutions per site.

velopment of practical applications for environmental measures such as bioremediation.

\section{Acknowledgments}

We are grateful to Dr Akifumi Ohtaka (Hirosaki University, Japan), Dr Yoshikazu Takashima (Hokkaido), Steven V. 
Fend (U.S. Geological Survey), and Dr Takafumi Nakano (Hiroshima University, Japan) for making suggestions about the taxonomic status and this manuscript. Also thanks to Katustoshi Ito (National Research Institute of Fisheries and Environment of Inland Sea) for providing us the material in this study, and to Anna Ansebo, Per Hjelmstedt, and Marcus Svensson for assistance in the molecular lab. Financial support to CE was provided by the Swedish Science Research Council.

\section{References}

Achurra, A. and Erséus, C. 2013. DNA barcoding and species delimitation: the Stylodrilus heringianus case (Annelida : Clitellata : Lumbriculidae). Invertebrate Systematics 27: 118-128.

Anisimova, M. and Gascuel, O. 2006. Approximate likelihood-ratio test for branches: A fast, accurate, and powerful alternative. Systematic Biology 55: 539-552.

Brinkhurst, R. O. and Baker, H. R. 1979. A review of the marine Tubificidae (Oligochaeta) of North America. Canadian Journal of $\mathrm{Zo}-$ ology 57: 1553-1569.

Cook, D. G. 1974. The systematics and distribution of marine Tubificidae (Annelida: Oligochaeta) in the Bahia de San Quintin, Baja California, with descriptions of five new species. Bulletin of the Southern California Academy of Sciences 73: 126-140.

Dinesh, A., Araki, S. K., Mukai, M., Kai, T., Kubota, K., Kawagoe, T., and Kubo, M. 2015. Development of an efficient bioremediation system for petroleum hydrocarbon contaminated soils based on hydrocarbon degrading bacteria and organic material control. Austin Journal of Biotechnology and Bioengineering 2: 1-7.

Erséus, C. 1981. Taxonomy of the marine genus Thalassodrilides (Oligochaeta, Tubificidae). Transactions of the American Microscopical Society 100: 333-344.

Erséus, C. 1990. The marine Tubificidae (Oligochaeta) of the barrier reef ecosystems at Carrie Bow Cay, Belize, and other parts of the Caribbean Sea, with description of twenty-seven new species and revision of Heterodrilus, Thalassodrilides and Smithsonidrilus. Zoologica Scripta 19: 243-303.

Erséus, C. 1992. The marine flora and fauna of Hong Kong and southern China III. Pp. 259-335. In: Morton, B. (Ed.) Proceedings of 4th International Marine Biological Workshop: The Marine Flora and Fauna of Hong Kong and Southern China, Hong Kong, 11-29 April 1989. Hong Kong University Press, Hong Kong.

Erséus, C., Rota, E., Matamoros, L., and De Wit, P. 2010. Molecular phylogeny of Enchytraeidae (Annelida, Clitellata). Molecular Phylogenetics and Evolution 57: 849-858.

Guindon, S., Dufayard, J. F., Lefort, V., Anisimova, M., Hordijk, W., and Gascuel, O. 2010. New algorithms and methods to estimate maximum-likelihood phylogenies: assessing the performance of PhyML 3.0. Systematic Biology 59: 307-321.

Guindon, S. and Gascuel, O. 2003. A simple, fast, and accurate algorithm to estimate large phylogenies by Maximum Likelihood. Systematic Biology 52: 696-704.

Ito, K., Ito, M., Onduka, T., Ohta, K., Torii, T., Hano, T., Mochida, K., Ohkubo, N., Miura, T., and Fujii, K. 2016. Differences in the ability of two marine annelid species, Thalassodrilides sp. and Perinereis nuntia, to detoxify 1-nitronaphthalene. Chemosphere 151: 339-344.

Martinsson, S., Achurra, A., Svensson, M., and Erséus, C. 2013. Integrative taxonomy of the freshwater worm Rhyacodrilus falciformis s.l. (Clitellata: Naididae), with the description of a new species. Zoologica Scripta 42: 612-622.

Ohtaka, A. 1987. New record of Tubificoides brevicoleus Baker (Oligochaeta, Tubificidae) from the Pacific coasts of Hokkaido, northern Japan. Journal of the Faculty of Science, Hokkaido University, Series VI, Zoology 25: 1-8.

Rambaut, A. 2014. FigTree v1.4.2. Available at http://tree.bio.ed.ac.uk/ software/figtree/ (3 February 2016).

Righi, G. and Kanner, E. 1979. Marine Oligochaeta (Tubificidae and Enchytraeidae) from the Caribbean Sea. Studies of the Fauna of Curaçao and other Caribbean Islands 58: 44-68.

Sayler, G. S., Sherrill, T. W., Perkins, R. E., Mallory, L. M., Shiaris, M. P., and Pedersen, D. 1982. Impact of coal-coking effluent on sediment microbial communities: a multivariate approach. Applied and Environmental Microbiology 44: 1118-1129.

Takashima, Y. 2000. Taxonomy of marine Tubificidae of Japan. (6) Subfamily Limnodriloidinae. Aquabiology 129: 398-402. [In Japanese]

Takashima, Y. 2001. Taxonomy of marine Tubificidae of Japan. (8) Subfamily Phallodrilinae. Aquabiology 132: 70-75. [In Japanese]

Takashima, Y. and Mawatari, S. F. 1996. Marine Tubificidae (Oligochaeta) from Hokkaido, northern Japan, with descriptions of two new species. Species Diversity 1: 55-70.

Takashima Y. and Mawatari, S. F. 1998. Mitinokuidrilus excavatus n. g., n. sp., a marine tubificid (Oligochaeta) with a unique mode of reproduction. Zoological Science 15: 593-597.

Tamura, K., Secher, G., Peterson, D., Filipski, A., and Kumar, S. 2013. MEGA6: Molecular Evolutionary Genetics Analysis version 6.0. Molecular Biology and Evolution 30: 2725-2729.

Vivien, R., Wyler, S., Lafont, M., and Pawlowski, J. 2015. Molecular barcoding of aquatic oligochaetes: implications for biomonitoring. PLoS ONE 10: e0125485.

Vorob'ev, D. S., Frank, Y. A., Lushnikov, S. V., Zaloznyi, N. A., and Noskov, Y. A. 2010. Oil decontamination of bottom sediments using Limnodrilus hoffmeisteri (Oligochaeta: Tubificidae). Contemporary Problems of Ecology 3: 15-18. 